Research Article

\title{
Reference Interval of Hemoglobin A1c and Influence of Hematological Parameters on Its Serum Concentration in Dogs
}

\author{
Stephan Neumann (iD \\ Small Animal Clinic, Institute of Veterinary Medicine, University of Goettingen, Burckhardtweg 2, D-37077, \\ Goettingen, Germany \\ Correspondence should be addressed to Stephan Neumann; sneuman@gwdg.de
}

Received 11 February 2020; Revised 11 August 2020; Accepted 24 September 2020; Published 7 October 2020

Academic Editor: Yoshiaki Hikasa

Copyright (C) 2020 Stephan Neumann. This is an open access article distributed under the Creative Commons Attribution License, which permits unrestricted use, distribution, and reproduction in any medium, provided the original work is properly cited.

\begin{abstract}
$\mathrm{HbAlc}$ could be an alternative to fructosamine as a marker for glucose levels over a longer period. In this study, we calculated a reference interval for $\mathrm{HbAlc}$ in dogs and investigated the correlation of $\mathrm{HbAlc}$ with hemoglobin and different hematological parameters. In total, 110 blood samples from dogs were investigated. Significant negative correlations were found between HbA1c and erythrocyte count, hemoglobin concentration, as well as hematocrit. There was a tendency in the red cell distribution width. No significant correlation was found in the reticulocyte number and the erythrocyte indices. In conclusion, there is an association of different blood parameters with the HbAlc concentration, which have to be considered for the interpretation of HbAlc.
\end{abstract}

\section{Introduction}

Diabetes mellitus is one of the most frequent endocrine diseases in dogs. Various studies have assessed the prevalence of diabetes mellitus which ranges between 0.3 and $1.3 \%$ [1-4]. The diagnosis of diabetes mellitus is based on compatible clinical signs and clinicopathological alterations such as hyperglycemia and glycosuria. However, blood glucose levels can vary widely, and measurement of a second parameter, which gives more information about the glucose level over a long period, is recommended.

Fructosamine gives an estimate of blood glucose concentration for the last 1-3 weeks because this is generally the half-life of albumin and other proteins that are bound with glucose $[5,6]$. This parameter is commonly used in animals, whereas in humans, instead of fructosamine, hemoglobin $\mathrm{A} 1 \mathrm{c}(\mathrm{HbAlc})$ is favored. $\mathrm{HbAlc}$ is part of the $\mathrm{HbA}$ fraction which can be divided into the subtypes HbAla1, HbAla2, $\mathrm{HbAlb}$, and HbAlc [7]. Plasma glucose binds to HbAlc during the whole life of erythrocytes and reflects the plasma glucose levels over the lifetime of an erythrocyte, which is three months in many species, for example, dogs. In humans, measurement of $\mathrm{HbAlc}$ instead of fructosamine for the diagnosis and monitoring of diabetes mellitus has been recommended since 2010/2011 [8]. This is due to the better correlation of HBA1c with blood glucose levels and a longer reflection of the average blood glucose concentrations compared to fructosamine [9]. Recently, some studies have investigated the use of $\mathrm{HbAlc}$ in dogs with diabetes mellitus [10-12]. There are some advantages in measuring HbAlc instead of fructosamine in dogs, for example, fructosamine is produced in the liver; thus, diseases of the liver influence the fructosamine serum concentration [13]. Furthermore, fructosamine is influenced by hyperbilirubinemia, hyperlipidemia, and azotemia $[6,14]$. Influences on the HbAlc serum concentration are rarely reported in veterinary medicine. However, because HbA1c is glycated hemoglobin, alterations in hemoglobin or erythrocyte concentrations and metabolisms may influence the HbAlc concentration. The aim of this study is to compare serum HbAlc concentrations with different hematological indices to see if there is an association of hemoglobin or erythrocytes with the HbA1c serum concentration, which have to be considered by the interpretation of $\mathrm{HbAlc}$ in dogs. 


\section{Materials and Methods}

2.1. Animals. In total, 110 dogs of different breeds, sex, and age were included in this study. All dogs were patients at the Small Animal Clinic, University of Goettingen. The samples for this prospective study were collected between April and November 2019. In all cases, blood samples were taken for diagnostic reasons. Blood samples were collected from healthy dogs $(n=45)$ for routine examination or from nonhealthy dogs $(n=65)$ including cases of diabetes mellitus $(n=2)$ and anemia $(n=10)$. All procedures were according to the German law on animal welfare.

2.2. Blood Sampling and Measurements. Blood samples from all dogs were collected from the cephalic vein. Blood for hematology was collected using an EDTA tube (Fa. Sarstedt AG and Co, Nümbrecht, Germany) and blood for the measurement of fructosamine, $\mathrm{HbAlc}$, and glucose was collected using a serum tube (Fa. Sarstedt AG and Co, Nümbrecht, Germany). Following collection, hematology parameters were investigated immediately using the ProCyte Dx Hematology Analyzer (IDEXX Laboratories Inc., One IDEXX Drive, Westbrook, Maine 04092, United States). The following parameters were investigated: hemoglobin $(\mathrm{Hb})$, erythrocyte count (RBC), hematocrit (HCT), red cell distribution width (RDW), reticulocytes, mean corpuscular volume (MCV), mean corpuscular hemoglobin $(\mathrm{MCH})$, and mean corpuscular hemoglobin concentration (MCHC).

Blood for the measurement of fructosamine, HbAlc, and glucose was centrifuged directly after sampling (3000 g/ $5 \mathrm{~min}$ ) (Fa. Eppendorf AG, Hamburg, Germany), and the measurement was obtained directly after centrifugation. Fructosamine was measured by a clinical chemistry analyzer (Konelab 20 i; Fa. Thermo Fischer Scientific Inc., Dreieich, Germany) and a commercial kit, using a colorimetric method with nitro blue tetrazolium (NBT). HbA1c was also measured by a clinical chemistry analyzer (Konelab 20 i; Fa. Thermo Fischer Scientific Inc., Dreieich, Germany) and a commercial kit. The principle of the test is a turbidimetric inhibition immunoassay. HbAlc reacts with anti-HbAlc antibody and forms a soluble antigen-antibody complex. A polyhapten reacts with the excess anti-HbA1c antibodies and forms insoluble antibody-polyhapten complexes, which are determined turbidimetrically. The imprecision of the test as determined by intra-assay and inter-assay coefficient of variation is $2.8 \%$ and $1.6 \%$, respectively.

2.3. Statistics. Statistical analysis was conducted using the program Prism 8 (GraphPad Software 2365 Northside Dr. Suite 560 San Diego, CA 92108, United States). The data were checked for normal distribution using the Kolmogorov-Smirnov test. For descriptive statistics, mean, minimum, and maximum were calculated. A linear regression analysis was used to assess the relationship between the different groups. A $p$ value less than 0.05 was considered statistically significant. The reference range was calculated using the following formula: mean $\pm 1.96 \times \mathrm{SD}$.

\section{Results}

3.1. Demographics. Different breeds of dogs were included without any marked breed prevalence. The age of the animals ranged between 0.5 and 14 years with a mean of 6.3 years. The sex distribution was almost equal with 55 female and 65 male dogs.

3.2. HbA1c. The level of HbA1c in all animals ranged between 6 and $43 \mathrm{mmol} / \mathrm{mol}$ and was normally distributed. Forty-five healthy dogs were used as controls. The range of $\mathrm{HbAlc}$ in this group was $17.1 \pm 3.56 \mathrm{mmol} / \mathrm{mol}$.

3.3. HbA1c and Hematological Parameters. As hematological parameters $\mathrm{Hb}, \mathrm{RBC}, \mathrm{HCT}, \mathrm{RDW}$, reticulocytes, MCV, $\mathrm{MCH}$, and $\mathrm{MCHC}$ were measured (Table 1). There was a weak to moderate correlation between $\mathrm{HbAlc}$ and fructosamine as well as glucose in our study $(r=0.175$; $p<0.0001 ; r=0.386 ; p<0.0001$ ) (Figures 1 and 2 ). The correlation with hemoglobin was weak $(r=0.127$; $p<0.0001$ ) but negative (Figure 3). A similar correlation was observed between $\mathrm{HbA1c}$ and red blood cells $(r=0.104$; $p=0.0004$ ) (Figure 4). A weak negative correlation existed between HbAlc and the hematocrit $(r=0.083 ; p=0.0017)$ (Figure 5). No significant correlation could be found to the number of reticulocytes $(r=0.011 ; p=0.248)$ (Figure 6) and the RDW ( $r=0.038 ; p=0.053$ ) (Figure 7$)$, and finally, no significant correlation was found when $\mathrm{HbAlc}$ was compared with the erythrocyte indices (MCV $r=0.0007$; $p=0.772 ; \mathrm{MCH} r=0.004 ; p=0.463 ; \mathrm{MCHC} r=0.02$; $p=0.126)$ (Figures 8-10).

\section{Discussion}

Following its first description in 1955 [15], it was more than 50 years before $\mathrm{HbA} 1 \mathrm{c}$ was recommended as the standard parameter for diabetes mellitus diagnosis and control in humans $[8,16]$. One of the reasons for this long delay was associated with the establishment of a standard measurement procedure. Today, HbA1c is measured with the HPLC ion exchange method, the affinity chromatography, the enzymatic assay, or the immunoassay, and the results are given in percent or $\mathrm{mmol} / \mathrm{mol}[10,12,16-18]$. The formula used to transform percent into $\mathrm{mmol} / \mathrm{mol}$ is as follows:

$$
\operatorname{HbA1c}(\%)=(0.09148 \times \operatorname{HbA} 1 \mathrm{c}(\mathrm{mmol} / \mathrm{mol}))+2.152[17] \text {. }
$$

From the described measurement methods, the immunoassay was the method we used for dogs in our study. Based on this method, reference intervals for HbAlc were calculated in humans as $20-42 \mathrm{mmol} / \mathrm{mol}$ [19] and in dogs as $5.3-20.7 \mathrm{mmol} / \mathrm{mol}$ [18] and $9.0-18.5 \mathrm{mmol} / \mathrm{mol}$, respectively [10]. In this study, the HbAlc serum concentration of healthy controls ranged from $13.5-20.6 \mathrm{mmol} / \mathrm{mol}$. Because the normal hemoglobin concentrations in humans and dogs are equal $(8.0-11.0 \mathrm{mmol} / \mathrm{l})$, the different reference intervals between both species cannot be explained by different hemoglobin concentrations. Comparing our HbAlc range in 
TABLE 1: Descriptive statistics of the hematological analytes.

\begin{tabular}{lcccccccc}
\hline & $\mathrm{Hb}(\mathrm{g} / \mathrm{dl})$ & $\mathrm{RBC}(\mathrm{M} / \mu \mathrm{l})$ & $\mathrm{HCT}(\%)$ & $\mathrm{RDW}(\%)$ & Retic. $(\mathrm{K} / \mu \mathrm{l})$ & $\mathrm{MCV}(\mathrm{fl})$ & $\mathrm{MCH}(\mathrm{pg})$ & $\mathrm{MCHC}(\mathrm{g} / \mathrm{dl})$ \\
\hline Min & 6.8 & 2.97 & 9.1 & 12.3 & 4.9 & 57 & 20 & 32 \\
Max & 22.2 & 9.96 & 61.7 & 21.2 & 183 & 73 & 26 & 38 \\
Mean & 16.7 & 7.19 & 50.1 & 16.9 & 44 & 65 & 23 & 35 \\
\hline
\end{tabular}

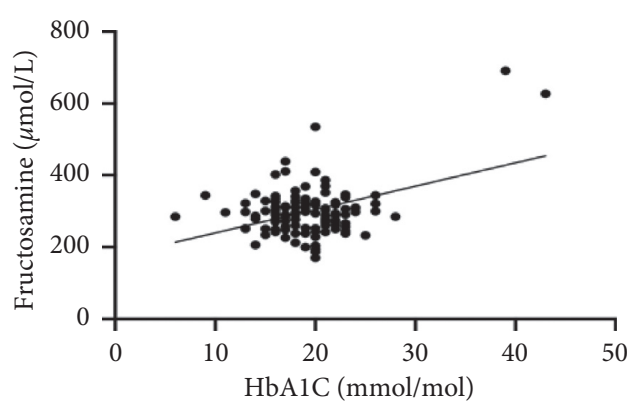

Figure 1: Relation between fructosamine and HbA1c $(r=0.175$; $p<0.0001)$.

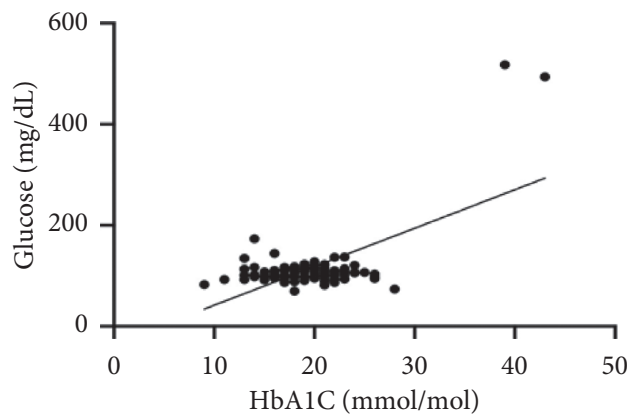

Figure 2: Relation between glucose and HbA1c $(r=0.386$; $p=0.0001)$.

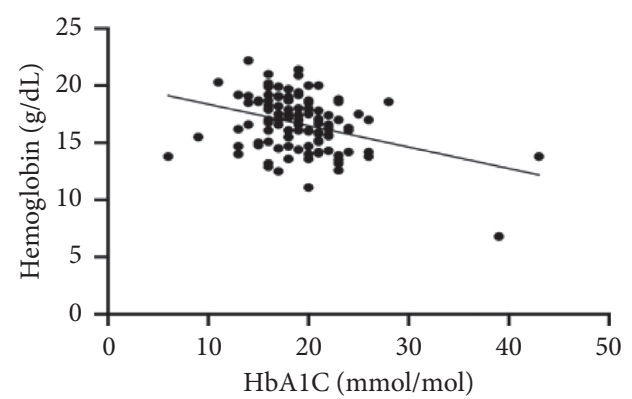

FIGURE 3: Relation between hemoglobin and HbA1C $(r=0.127$; $p<0.0001)$.

healthy controls with the other canine studies $[10,18]$, we found comparable upper limits, but a difference between the lower limits. We do not have any explanation for this difference because the inclusion criteria for reference dogs are equal in the different studies. For clinical purposes, just the upper limit is of importance [12], so the difference in the lower limits is without any clinical relevance.

Today, HbA1c is the gold standard for the assessment of serum glucose concentration over a longer period in human medicine [20]. In former times and in veterinary medicine,

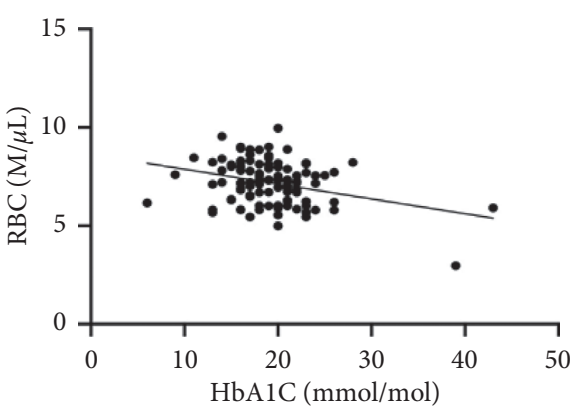

Figure 4: Relation between red blood cells and HbA1c $(r=0.104$; $p<0.0004)$.

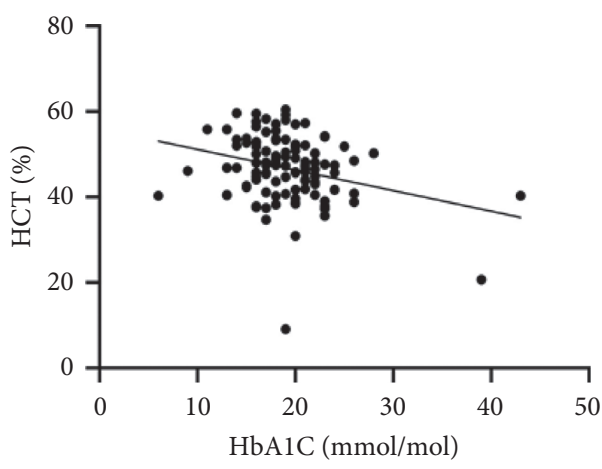

FIgURE 5: Relation between hematocrit and HbA1c $(r=0.083$; $p=0.0017)$.

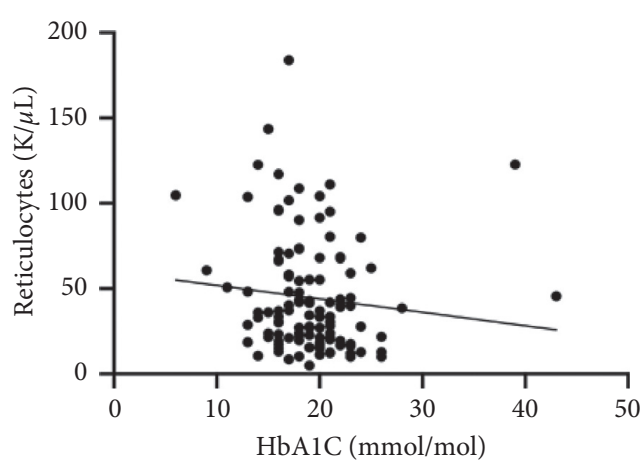

FIGURE 6: Relation between the reticulocyte number and HbAlc $(r=0.011 ; p=0.248)$.

long-term hyperglycemia (1-3 weeks) is diagnosed by an elevated fructosamine concentration. Different human and veterinary studies show a significant correlation between HbAlc and fructosamine $[11,18,20-22]$. This was confirmed in our study. We found a weak to moderate correlation between $\mathrm{HbAlc}$ and fructosamine or glucose. Other studies showed a high correlation between $\mathrm{HbAlc}$ and 


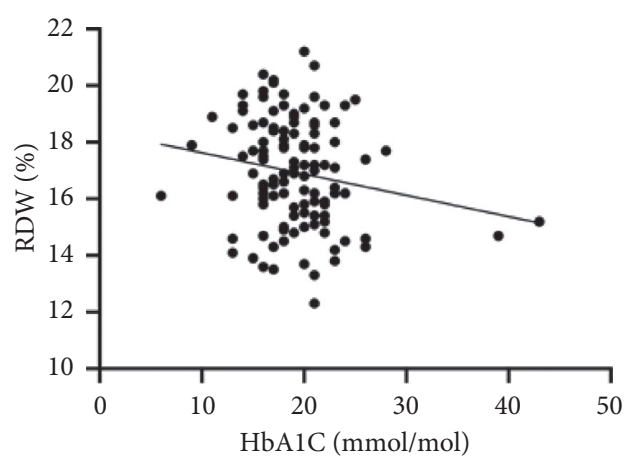

FIGURE 7: Relation between the red cell distribution width and HbAlc $(r=0.038 ; p=0.053)$.

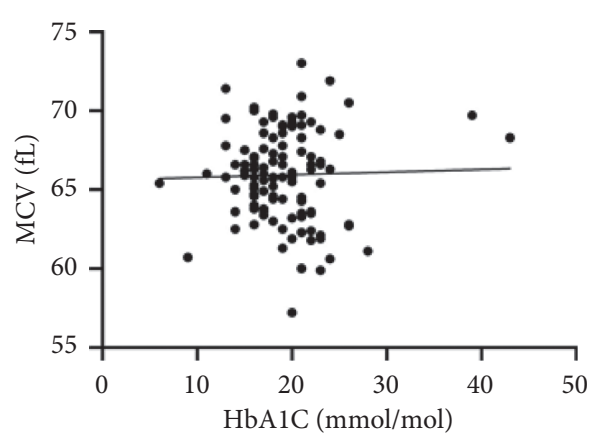

Figure 8: Relation between $\mathrm{MCV}$ and HbAlc $(r=0.0007$; $p=0.772)$.

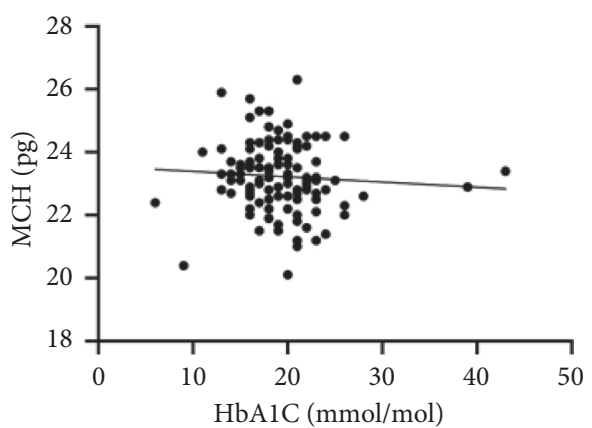

Figure 9: Relation between $\mathrm{MCH}$ and HbA1c $(r=0.0047$; $p=0.463)$.

fructosamine, but in these studies, more diabetic patients were considered, having an influence on the significance $[11,18]$.

Based on the physiology of HbAlc, an influence of different alterations in hemoglobin metabolism or erythrocytes on $\mathrm{HbAlc}$ is possible. Various studies have compared hematological parameters with $\mathrm{HbAlc}$ in humans, and inverse correlations with different parameters including hemoglobin and erythrocyte indices such as MVC were found [23-25]. In veterinary medicine, only a few studies have investigated $\mathrm{HbA} 1 \mathrm{c}$ in cases of anemia and compared $\mathrm{HbA1c}$ with hematological parameters $[14,18]$. Correlations between $\mathrm{HbAlc}$ and hematological parameters were inconsistent. In our study, we found a weak negative

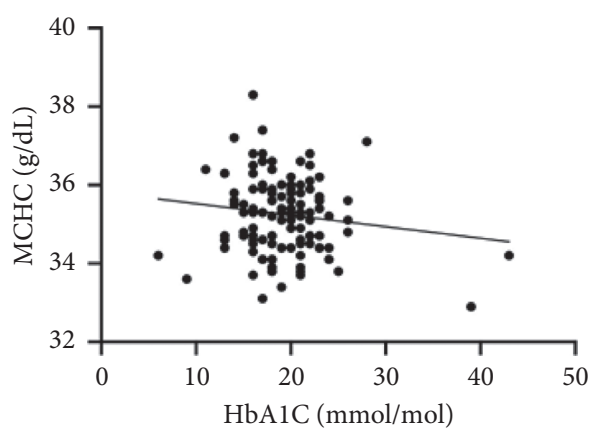

Figure 10: Relation between MCHC and HbA1c $(r=0.02$; $p=0.126)$.

correlation between HbA1c and hemoglobin, the RBC, and the HCT. As HbA1c is part of hemoglobin, it is probable that alterations in hemoglobin or the RBC also induce HbA1c alterations. This was confirmed by the results of our study. In contrast to other studies, we could not confirm a relationship between HbAlc and erythrocyte indices. This is may be a consequence of a low number of anemic dogs in our study population $(n=10)$. In our study, there was a correlation tendency between $\mathrm{HbA} 1 \mathrm{c}$ and RDW. This was confirmed by other studies, where HbA1c significantly correlated with RDW [26, 27]. The reason for this tendency is not clear because the RDW is a parameter of erythrocyte volume like $\mathrm{MCV}$, which does not correlate with HbAlc. Furthermore, we also found no correlation between $\mathrm{HbAlc}$ and the reticulocyte count.

In one study, a combination of HbAlc and HCT was used to detect gestational diabetes mellitus in humans [28]. In our study, we could not confirm this observation as we did not include enough dogs with diabetes mellitus, but a significant correlation between HbA1c and HCT was observed.

\section{Data Availability}

The data used to support the findings of this study are available from the author upon request.

\section{Conflicts of Interest}

The author declares no conflicts of interest.

\section{Acknowledgments}

The author thanks Hannah Linnenkohl for her support.

\section{References}

[1] L. J. Davison, M. E. Herrtage, and B. Catchpole, "Study of 253 dogs in the United Kingdom with diabetes mellitus," Veterinary Record, vol. 156, no. 15, pp. 467-471, 2005.

[2] F. Fracassi, M. Pietra, A. Boari, G. Aste, M. Giunti, and P. Famigli-Bergamini, "Breed distribution of canine diabetes mellitus in Italy," Veterinary Research Communications, vol. 28, pp. 339-342, 2004.

[3] L. Guptill, L. Glickman, and N. Glickman, "Time trends and risk factors for diabetes mellitus in dogs: analysis of veterinary 
medical data base records (1970-1999)," The Veterinary Journal, vol. 165, no. 3, pp. 240-247, 2003.

[4] M. Mattin, D. O’Neill, D. Church, P. D. McGreevy, P. C. Thomson, and D. Brodbelt, "An epidemiological study of diabetes mellitus in dogs attending first opinion practice in the UK," Veterinary Record, vol. 174, no. 14, p. 349, 2014.

[5] R. J. Benjamin and D. B. Sacks, "Glycated protein update: implications of recent studies, including the diabetes control and complications trial," Clinical Chemistry, vol. 40, no. 5, pp. 683-687, 1994.

[6] M. Kawamoto, J. J. Kaneko, A. A. Heusner et al., "Relation of fructosamine to serum protein, albumin and glucose concentrations in helthy and diabetic dogs," American Journal of Veterinary Research, vol. 53, pp. 851-855, 1992.

[7] S. I. Sherwani, H. A. Khan, A. Ekhzaimy et al., "Significance of HbAlc test in diagnosis and prognosis of diabetic patients," Biomarker Insights, vol. 11, pp. 95-104, 2016.

[8] American Diabetes Association, "Standards of medical care in diabetes-2010," Diabetes Care, vol. 33, pp. 11-61, 2010.

[9] H. S. Chen, R. L. Chen, Z. Y. Chang et al., "The response of $\mathrm{GHb}$ to stepwise plasma glucose change over time in diabetic patients," Diabetes Care, vol. 16, pp. 1313-1314, 1993.

[10] A. F. Goemans, S. J. Spence, and I. K. Ramsey, "Validation and determination of a reference interval for canine $\mathrm{HbAlc}$ using an immunoturbidimetric assay," Veterinary Clinical Pathology, vol. 46, no. 2, pp. 227-237, 2017.

[11] N.-Y. Kim, J. An, J.-K. Jeong et al., "Evaluation of a human glycated hemoglobin test in canine diabetes mellitus," Journal of Veterinary Diagnostic Investigation, vol. 31, no. 3, pp. 408-414, 2019.

[12] I. L. Oikonomidis, T. K. Tsouloufi, N. Soubasis, and M. Kritsepi-Konstantinou, "Validation, reference intervals and overlap performance of a new commercially available automated capillary electrophoresis assay for the determination of the major fraction of glycated haemoglobin (HbAlc) in dogs," The Veterinary Journal, vol. 234, pp. 48-54, 2018.

[13] S. Neumann and G. Fabig, "Fructosamine concentration in dogs with hepatopathy," Kleintierpraxis, vol. 49, pp. 293-298, 2004.

[14] C. E. Reusch and B. Haberer, "Evaluation of fructosamine in dogs and cats with hypo- or hyperproteinaemia, azotaemia, hyperlipidaemia and hyperbilirubinaemia," Veterinary Record, vol. 148, no. 12, pp. 370-376, 2001.

[15] H. G. Kunkel and G. Wallenius, "New hemoglobin in normal adult blood," Science, vol. 122, no. 3163, p. 288, 1955.

[16] World Health Organization (WHO), Use of Glycated Haemoglobin (HbA1c) in the Diagnosis of Diabetes Mellitus: Abbreviated Report of a WHO Consultation, WHO, Geneva, Switerzland, 2011.

[17] L. Ding, Y. Xu, S. Liu, Y. Bi, and Y. Xu, "Hemoglobin A1c and diagnosis of diabetes," Journal of Diabetes, vol. 10, no. 5, pp. 365-372, 2018.

[18] A. Loste and M. C. Marca, "Fructosamine and glycated hemoglobin in the assessment of glycaemic control in dogs," Veterinary Research, vol. 32, no. 1, pp. 55-62, 2001.

[19] C. Bi, "HbAlc: a review of analytical and clinical aspects," Annals of Laboratory Medicine, vol. 33, no. 6, pp. 393-400, 2013.

[20] R. T. Ribeiro, M. P. Macedo, and J. F. Raposo, "HbA1c, fructosamine, and glycated albumin in the detection of dysglycaemic conditions," Current Diabetes Review, vol. 12, pp. 14-19, 2016.

[21] A. Jensen, "Glycated blood proteins in canine diabetes mellitus," Veterinary Record, vol. 137, no. 16, pp. 401-405, 1995.
[22] N. Mendes, M. Alves, R. T. Ribeiro, A. L. Papoila, and F. Serrano, "Association between glycated albumin, fructosamine, and $\mathrm{HbAlc}$ with neonatal outcomes in a prospective cohort of women with gestational diabetes mellitus," International Journal of Gynecology \& Obstetrics, vol. 146, no. 3, pp. 326-332, 2019.

[23] P. S. Hardikar, S. M. Joshi, D. S. Bhat et al., "Spuriously high prevalence of prediabetes diagnosed by HbAlc in young Indians partly explained by hematological factors and iron deficiency anemia," Diabetes Care, vol. 35, no. 4, pp. 797-802, 2012.

[24] S. Inada and M. Koga, "HbA1c and glycated albumin levels are high in gastrectomized subjects with iron-deficiency anemia," Annual Clinical and Laboratory Science, vol. 47, pp. 52-57, 2017.

[25] M. Koga, S. Morita, H. Saito, M. Mukai, and S. Kasayama, "Association of erythrocyte indices with glycated haemoglobin in pre-menopausal women," Diabetic Medicine, vol. 24, no. 8, pp. 843-847, 2007.

[26] X. Bao, M. Wan, Y. Gu et al., "Red cell distribution width is associated with hemoglobin A1C elevation, but not glucose elevation," Journal of Diabetes and Its Complications, vol. 31, no. 10, pp. 1544-1548, 2017.

[27] A. R. Bhutto, A. Abbasi, and A. H. Abro, "Correlation of hemoglobin A1c with red cell width distribution and other parameters of red blood cells in type II diabetes mellitus," Cureus, vol. 230, 2019.

[28] K. Wu, Y. Cheng, T. Li et al., "The utility of HbAlc combined with haematocrit for early screening of gestational diabetes mellitus," Diabetology \& Metabolic Syndrome, vol. 10, no. 1, 2018. 